FUNCTIONAL BOWEL DISEASE

\title{
Cyclooxygenase 2 mediates post-inflammatory colonic secretory and barrier dysfunction
}

\author{
S R Zamuner, N Warrier, A G Buret, W K MacNaughton, J L Wallace
}

Gut 2003;52:1714-1720

See end of article for authors' affiliations

Correspondence to:

Dr J L Wallace,

Department of

Pharmacology and

Therapeutics, University of

Calgary, 3330 Hospital

Drive NW, Calgary,

Alberta, $\mathrm{T} 2 \mathrm{~N} 4 \mathrm{~N} 1$

Canada; wallacej@

ucalgary.ca

Accepted for publication 1 July 2003
Background and aims: The colonic epithelium plays a key role in host defence. During colitis, epithelial function is impaired, leading to elevated bacterial translocation and exacerbation of inflammation. We previously documented perturbation of epithelial function, in terms of secretion and as a barrier to bacterial translocation, that persisted long after resolution of a bout of colitis in the rat. The mechanisms underlying the epithelial dysfunction are not completely understood.

Methods: Given the ability of prostaglandin (PG) $D_{2}$ to suppress colonic epithelial secretion, we investigated the potential roles of this eicosanoid and of cyclooxygenase 2 (COX-2) in mediating postcolitis epithelial secretory and barrier dysfunction.

Results: Six weeks after induction of colitis with trinitrobenzene sulphonic acid, there was marked elevated synthesis of $\mathrm{PGD}_{2}$ and elevated COX-2 expression. Selective COX-2 inhibition abolished the increase in $\mathrm{PGD}_{2}$ synthesis. Colonic chloride secretory responses (in vitro) were significantly diminished relative to those in controls, a defect that was reversed by pre-exposure to a selective COX-2 inhibitor (celecoxib) but not to a selective COX-1 inhibitor (SC-560). The hyporesponsiveness was mimicked by pre-exposure of normal colonic tissue to $P G D_{2}$, but not to its metabolite, $15-$ deoxy- $\Delta^{12-14} P G J_{2}$. The post-colitis rats exhibited a 10-fold increase in bacterial colonisation of the colon, and $>3$-fold increase in bacterial translocation. Twice daily treatment for one week with a selective COX-2 inhibitor (rofecoxib) did not affect bacterial colonisation but abolished the increase in bacterial translocation.

Conclusions: These studies demonstrate an important role for COX-2, possibly via generation of $\mathrm{PGD}_{2}$, in mediating the prolonged epithelial secretory and barrier dysfunction after a bout of colitis in the rat.
$\mathrm{T}$ he gastrointestinal tract is continuously exposed to toxins, microbes, microbial products, and other antigens The intestinal epithelium plays several important functions in protecting an organism from the potential deleterious effects of these agents, such as acting as a physical barrier that limits the entry of luminal substances and microorganisms into the lamina propria. This barrier is established through the formation of tight junctions between neighbouring epithelial cells. Secretion of water is another mechanism through which the intestinal epithelium reduces the ability of luminal agents, such as bacteria, to gain access to the lamina propria. Active secretion of chloride ions by the epithelium is the driving force for water secretion. ${ }^{1}$ This secretion acts to flush away bacteria and noxious substances, ${ }^{2}$ as well as providing a vehicle for the delivery of secretory IgA into the lumen.

Numerous studies have documented impairment of epithelial secretion and epithelial barrier function during acute intestinal inflammation..$^{3-6}$ Recently, we demonstrated that in the rat, such dysfunction persists long after resolution of the inflammatory response (at least 26 weeks). We have suggested that such a prolonged impairment of host defence may contribute to recurrent bouts of inflammation in diseases such as inflammatory bowel disease, as well as symptom generation in disorders such as post-infectious irritable bowel syndrome. ${ }^{78}$ The secretory dysfunction was present despite the absence of any histologically detectable inflammation or elevation of tissue myeloperoxidase (MPO) activity and despite the lack of any detectable alteration of epithelial permeability. ${ }^{78}$ Nevertheless, there was a threefold increase in the incidence of bacterial translocation. ${ }^{7}$

There are many mediators that are known to modulate chloride secretion, including nitric oxide (NO), histamine, serotonin, and leukotrienes. ${ }^{9-13}$ Previous studies using experi- mental colitis and radiation enteritis models have pointed to an important contribution of NO derived from the inducible form of NO synthase in prolonged epithelial secretory dysfunction. ${ }^{714}$ For example, expression of iNOS was found to be upregulated in the colon of rats six weeks after administration of trinitrobenzene sulphonic acid (TNBS), and the epithelial hyporesponsiveness to electrical field stimulation (EFS) and to isobutylmethylxanthine (IBMX) could be partially reversed by pre-exposure to a selective inducible nitric oxide synthase (iNOS) inhibitor. ${ }^{7}$

Prostaglandins (PG) also appear to play an important role in modulating colonic epithelial secretion. These mediators are closely associated with acute inflammatory conditions, contributing to oedema formation through their vasodilator effects, and to the generation of hyperalgesia. In recent years, the anti-inflammatory properties of PG have become better appreciated. For example, in a model of pleuritis in the rat, cyclooxygenase 2 (COX-2) expression was increased to the greatest extent during resolution of the inflammatory reaction. ${ }^{15}$ Moreover, generation of $\mathrm{PGD}_{2}$ from COX-2 was shown to be crucial in reducing leucocyte infiltration to the site of inflammation during the resolution phase. These effects may have been in part due to the actions of a metabolite of $\mathrm{PGD}_{2}$, namely 15 -deoxy- $\Delta^{12-14} \mathrm{PGJ}_{2}$ (subsequently abbreviated as $\Delta \mathrm{PGJ}_{2}$ ). We previously reported that colonic $\mathrm{PGD}_{2}$ generation via $\mathrm{COX}-2$ downregulates granulo-

\footnotetext{
Abbreviations: COX, cyclooxygenase; MPO, myeloperoxidase; NO, nitric oxide; TNBS, trinitrobenzene sulphonic acid; EFS, electrical field stimulation; IBMX, isobutylmethylxanthine; iNOS, inducible nitric oxide synthase; PG, prostaglandins; $\triangle P G J_{2}, 15$-deoxy- $\Delta^{12-14} P G J_{2} ; P D$, potential difference; $I_{\mathrm{sc}}$, short circuit current; LPS, lipopolysaccharide; CFU, colony forming units
} 
cyte infiltration. ${ }^{16} \mathrm{PGD}_{2}$ exerts antisecretory effects in both the canine ${ }^{17}$ and rat colon. ${ }^{18}$ Taken together, these studies raise the possibility that $\mathrm{PGD}_{2}$ derived from COX-2 could play a key role in the secretory hyporesponsiveness that persists after resolution of a bout of colitis. This hypothesis was tested in the present study. In addition, we examined the potential contribution of COX-2 to the barrier dysfunction that persists after resolution of colitis.

\section{MATERIALS AND METHODS \\ Animals}

Male Wistar rats (175-200 g) were obtained from Charles River Breeding Farms (Montreal, PQ, Canada). Rats were allowed free access to standard laboratory rodent chow and tap water. All experiments were approved by the Animal Care Committee of the University of Calgary and were performed in accordance with the guidelines of the Canadian Council on Animal Care.

\section{Induction of colonic inflammation}

Colitis was induced as previously described. ${ }^{8}{ }^{19}$ Briefly, rats were lightly anaesthetised with halothane and an infant feeding tube fitted onto a blunt 18 gauge needle was inserted rectally. The tip of the tube was placed approximately $8 \mathrm{~cm}$ into the colon and $30 \mathrm{mg}$ of TNBS in $0.5 \mathrm{ml}$ of $50 \%$ ethanol was instilled. Naïve age matched rats served as controls. At various times after induction of colitis, rats were anaesthetised with halothane and then killed by cervical dislocation. The severity of colonic damage was blindly scored on a $0-10$ scale using criteria that have previously been reported in detail..$^{20}$ Briefly, a score of 0 represents normal appearance, a score of 1 is given for focal hyperaemia but no ulcers, a score of 2 is given for ulceration without associated inflammation, and a score of 3 or greater is given when ulceration and inflammation are both evident (the score increasing with the extent of ulceration). After scoring, a sample of the distal colon was frozen for subsequent measurement of MPO activity as an index of granulocyte infiltration. $^{20}$

\section{Electrolyte transport}

A segment of the distal colon was removed and the faecal contents were gently washed away. The external muscle layer was carefully removed. ${ }^{721}$ The stripped colonic tissue was mounted in an Ussing-type chamber (Navicyte, Sparks, Nevada, USA). Tissues were bathed in modified Krebs buffer ( $115.0 \mathrm{mM} \mathrm{NaCl} ; 2.0 \mathrm{mM} \mathrm{KH} \mathrm{PO}_{4} ; 2.4 \mathrm{mM} \mathrm{MgCl}$; $1.3 \mathrm{mM}$ $\mathrm{CaCl}_{2} ; 8.0 \mathrm{mM} \mathrm{KCl}$; and $25.0 \mathrm{mM} \mathrm{NaHCO} 3$ ) at $37^{\circ} \mathrm{C}$ and oxygenated with a gas mixture of $95 \% \mathrm{O}_{2} / 5 \% \mathrm{CO}_{2}$. The serosal chamber was bathed in buffer containing $10 \mathrm{mM}$ glucose whereas the mucosal buffer contained $10 \mathrm{mM}$ mannitol. Potential difference (PD) was clamped to zero using a voltage clamp apparatus (EVC-4000; World Precision Instruments, Sarasota, Florida, USA) and the short circuit current $\left(\mathrm{I}_{\mathrm{sc}}\right)$ was measured by a digital data acquisition system (MP 100; Biopac Systems, Santa Barbara, California, USA) and analysis software (AcqKnowledge 3.5.7; Biopac). Conductance was calculated from PD and $\mathrm{I}_{\mathrm{sc}}$ using Ohm's law. The tissue was allowed to equilibrate for 20 minutes before incubation with drugs or stimulation. $\mathrm{I}_{\mathrm{sc}}$ responses to $\mathrm{EFS}(50 \mathrm{~V}, 10 \mathrm{~Hz}$, 5 seconds) delivered by a Grass S48 stimulator and SIU50 stimulus isolation unit (Grass Instruments, Warwick, Rhode Island, USA) were measured. IBMX $300 \mu \mathrm{M}$ or vehicle (Krebs buffer) was added serosally in the same colonic preparation and the change in $\mathrm{I}_{\mathrm{sc}}$ was measured. The concentration of IBMX was selected on the basis of the results of previous studies in which hyporesponsiveness to this secretagogue was observed in rats after resolution of colitis. ${ }^{7}$

\section{Role of COX-2 and $\mathrm{PGD}_{2}$ in epithelial}

\section{hyporesponsiveness}

To examine the role of COX-2 and $\mathrm{PGD}_{2}$ in the hyporesponsiveness of colonic tissue to stimulation by IBMX and EFS, we tested the effects of selective COX-2 (celecoxib $10 \mu \mathrm{M}$ ) and COX-1 (SC-560 $300 \mathrm{nM}$ ) inhibitors. After mounting in the Ussing chambers, the tissues were exposed to one of these inhibitors or vehicle for 10 minutes prior to stimulation with IBMX or EFS and the short circuit current responses were measured, as above. Celecoxib and SC-560 were initially dissolved in dimethylsulphoxide. The final concentration of dimethylsulphoxide in the Ussing chamber was $0.1 \%$.

Additional studies were performed using colonic tissue from control rats in which the tissue was preincubated with $\mathrm{PGD}_{2}(1 \mu \mathrm{M})$, the metabolite $\Delta \mathrm{PGJ}_{2}(1 \mu \mathrm{M})$, or vehicle. These prostanoids were initially dissolved in ethanol. The final concentration of ethanol in the Ussing chamber was $0.1 \%$. $\mathrm{I}_{\mathrm{sc}}$ responses to IBMX and EFS were then measured.

\section{Prostaglandin synthesis and COX-2 expression}

Groups of 5-6 rats each were killed on day 1, and one, two, and six weeks after intracolonic TNBS or saline (control) administration. Colonic tissue was collected and processed for measurements of $\mathrm{PGE}_{2}$ and $\mathrm{PGD}_{2}$, as described previously. ${ }^{16}$ Levels of prostaglandins generated by the tissue samples were measured using specific commercially available ELISA kits. ${ }^{16}$

Colonic tissue was also taken from rats killed six weeks after TNBS or saline administration for examination of COX2 expression by western blotting. Additional groups of rats (control and post-TNBS; $\mathrm{n}=6$ each) were given lipopolysaccharide (LPS; Escherichia coli serotype 0111:B4) intraperitoneally, and rats were killed six hours later. Tissue samples were taken for assessment of COX-2 expression by western blotting. For all western blot experiments, tissue samples were homogenised in lysis buffer $(0.1 \%$ Triton X-100, $50 \mu \mathrm{M}$ pepstatin-A, $0.2 \mathrm{mM}$ leupeptin, $1 \mu \mathrm{g} / \mathrm{ml}$ aprotinin, $10 \mathrm{mg} / \mathrm{ml}$ phenylmethyl sulphonyl fluoride, $50 \mathrm{mM}$ Tris, and $10 \mathrm{mM}$ EDTA). Samples were then centrifuged and the protein concentration of the supernatant was determined by colorimetric assay (BioRad, Hercules, California, USA). Protein $(50 \mu \mathrm{g})$ was separated on a $10 \%$ polyacrylamide gel and then transferred to a nitrocellulose membrane. The membrane was incubated for one hour with blocking buffer $(20 \mathrm{mM}$ Tris, $100 \mathrm{mM} \mathrm{NaCl}, 0.5 \%$ Tween 20, and 5\% non-fat dried milk) and then probed overnight with a polyclonal rabbit antibody against COX-2 (1:500; Cayman Chemical, Ann Arbor, Michigan, USA). The membrane was then incubated with a donkey antirabbit IgG secondary antibody conjugated to horseradish peroxidase (Amersham, Little Chalfont, UK) for one hour at room temperature. A chemiluminescence reagent (Amersham) was added to visualise the labelling according to the manufacturer's instructions. Densitometry was done using a GS-710 Calibrated Imaging Densitometer (BioRad) and analysed with Quantity One software (BioRad).

\section{Bacterial translocation and colonic bacterial colonisation}

Bacterial translocation and colonic bacterial colonisation in rats six weeks after TNBS administration and in age matched controls were determined as described previously. ${ }^{72}$ For bacterial translocation, we examined colonisation of the spleen. As in our previous study, ${ }^{7}$ any sample having more than 20 colony forming units (CFU) per gram of tissue was classified as positive for translocation of bacteria. For bacterial colonisation, we measured total numbers of aerobes, as in our previous study ${ }^{7}$ we had observed changes in aerobic colonisation and translocation, but not in anaerobic colonisation or translocation. A segment of colon including 
luminal contents was placed in $5 \mathrm{ml}$ of sterile phosphate buffered saline ( $\mathrm{pH}$ 7.4). The samples were weighed, homogenised, and diluted prior to plating of $0.1 \mathrm{ml}$ of each dilution on blood agar plates. The number of CFU/g tissue was recorded for both control and post-colitis rats.

To examine the contribution of COX-2 to any observed changes in bacterial translocation and/or bacterial colonisation, groups of 10-11 rats each were treated twice daily with rofecoxib ( $3 \mathrm{mg} / \mathrm{kg}$ orally) during the sixth week after TNBS administration. A group of control rats (no TNBS; $n=10$ ) was treated with vehicle at the same times. The choice of rofecoxib as a selective COX-2 inhibitor for these in vivo studies, as opposed to celecoxib in the in vitro studies, was entirely based on our having an adequate supply of the former for this multiple dosing study. The dose of rofecoxib was selected based on our previous demonstration that it produced significant inhibition of COX-2 in the rat without affecting COX-1 activity. ${ }^{23}$

\section{Materials}

TNBS was obtained from Fluka Chimika (Buchs, Switzerland). IBMX, carbachol, and LPS were purchased from Sigma Chemical Company (St Louis, Missouri, USA). $\mathrm{PGD}_{2}$ and $\triangle \mathrm{PGJ}_{2}$ were obtained from Cayman Chemical Company (Ann Arbor, Michigan, USA). Rofecoxib and celecoxib were generous gifts from NicOx (Sophia Antipolis, France), while SC-560 was provided by BoehringerIngelheim (Ingelheim, Germany).

\section{Statistical analysis}

All data are expressed as mean (SEM). Comparisons among groups of data were made using a one way analysis of variance followed by the Student-Newman-Keuls test. An associated probability ( $\mathrm{p}$ value) of less than 5\% was considered significant.

\section{RESULTS}

As in our previous studies, ${ }^{89}$ colonic tissue taken from rats six weeks after administration of TNBS did not exhibit any macroscopic or histological signs of damage or inflammation. Colonic damage scores in the post-colitis group (1.2 (0.4); $\mathrm{n}=14$ ) were not significantly different from those in controls (0.9 (0.2); $\mathrm{n}=12)$. Colonic MPO activity in post-colitis rats (3.9 (0.6) U/mg; $\mathrm{n}=14$ ) was not significantly different from that in controls (3.2 (0.4) U/mg; $\mathrm{n}=12)$.

\section{Prostaglandin synthesis and COX-2 expression}

Administration of TNBS resulted in a marked increase in colonic synthesis of both $\mathrm{PGE}_{2}$ and $\mathrm{PGD}_{2}$ (fig 1). Synthesis of $\mathrm{PGE}_{2}$ was significantly elevated above basal levels at one day and one week post-TNBS, but had returned to basal levels by two weeks post-TNBS. Changes in $\mathrm{PGD}_{2}$ after TNBS administration followed a very different pattern. There was a significant increase in $\mathrm{PGD}_{2}$ synthesis one day after TNBS, a return towards basal levels at one week, and a second increase in $\mathrm{PGD}_{2}$ synthesis at two weeks that remained evident at six weeks post-TNBS. Thus the greatest increase in $\mathrm{PGD}_{2}$ synthesis was observed during the period when healing of the colonic injury occurred.

To determine the contribution of COX-2 to the elevated synthesis of $\mathrm{PGD}_{2}$ in post-colitis rats, we examined the effects of twice daily treatment with rofecoxib $(3 \mathrm{mg} / \mathrm{kg}$ orally) during the sixth week post-TNBS on colonic $\mathrm{PGD}_{2}$ synthesis. As shown by the square symbols in fig 1 , rofecoxib suppressed colonic $\mathrm{PGD}_{2}$ synthesis to basal levels. These observations therefore suggest that colonic synthesis of $\mathrm{PGD}_{2}$ at six weeks post-TNBS occurred primarily via COX-2.

To further explore the possibility that the elevated colonic $\mathrm{PGD}_{2}$ synthesis was occurring via COX-2, expression of

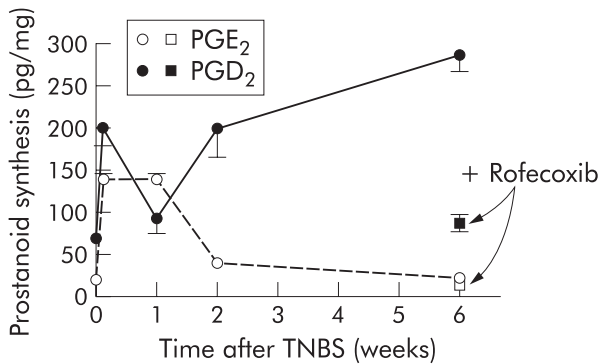

Figure 1 Colonic synthesis of prostaglandins $E_{2}$ and $D_{2}$ at various times after intracolonic administration of trinitrobenzene sulphonic acid (TNBS). PGE 2 synthesis was significantly $(p<0.05)$ elevated above basal levels at one day to one week after TNBS administration. $P G D_{2}$ synthesis was significantly elevated at one day and at two and six weeks postTNBS. The square symbols show colonic synthesis of $\mathrm{PGD}_{2}$ (filled) and $\mathrm{PGE}_{2}$ (open) in rats treated twice daily during the sixth week post-TNBS with the selective COX-2 inhibitor rofecoxib (3 mg/ $\mathrm{kg}$ orally). PGD synthesis was significantly $(p<0.01)$ reduced by rofecoxib treatment.

COX-2 in the colon was examined by western blotting. In post-colitis rats, COX- 2 was elevated by only $56 \%$ above that in controls $(\mathrm{p}<0.05)$ (fig 2$)$. However, it was possible that
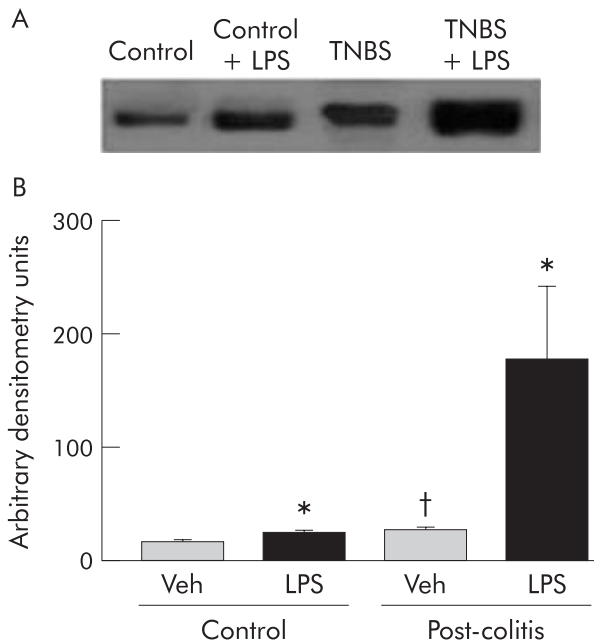

Figure 2 Colonic expression of cyclooxygenase 2 (COX-2) in rats six weeks after trinitrobenzene sulphonic acid (TNBS) administration and in age matched controls. Subgroups of rats were treated with lipopolysaccharide (LPS) from Escherichia coli six hours prior to the samples being taken. Representative western blots are shown (A). (B) Densitometry data for $5-9$ rats per group. ${ }^{*} p<0.05$ versus the corresponding vehicle (Veh) treated group; $\mathrm{p}<0.05$ versus the control vehicle treated group.

Table 1 Basal short circuit current $\left(\mu \mathrm{A} / \mathrm{cm}^{2}\right)$ in colonic tissue from control and post-colitis rats

\begin{tabular}{lll}
\hline Treatment & Control & Post-colitis \\
\hline Vehicle & $81(9)$ & $44(8) \dagger$ \\
Celecoxib $(10 \mu \mathrm{M})$ & $26(7)^{*}$ & $28(15)$ \\
SC-560 $(300 \mathrm{nM})$ & $57(17)$ & $52(7)$ \\
PGD $_{2}(1 \mu \mathrm{M})$ & $30(3)^{*}$ & $21(3)^{*}$
\end{tabular}

None of the vehicles used $10.1 \%$ dimethylsulphoxide for celecoxib and SC-560; $0.1 \%$ ethanol for prostaglandin $D_{2}$ ) significantly affected short circuit current (or baseline conductance) and so were pooled for presentation in this table. However, statistical analysis was performed using only data from the appropriate vehicle treated rats. ${ }^{*} p<0.05$ versus the corresponding vehicle treated group; $t p<0.01$ versus the corresponding control group ( $n \geqslant 5$ per group). 

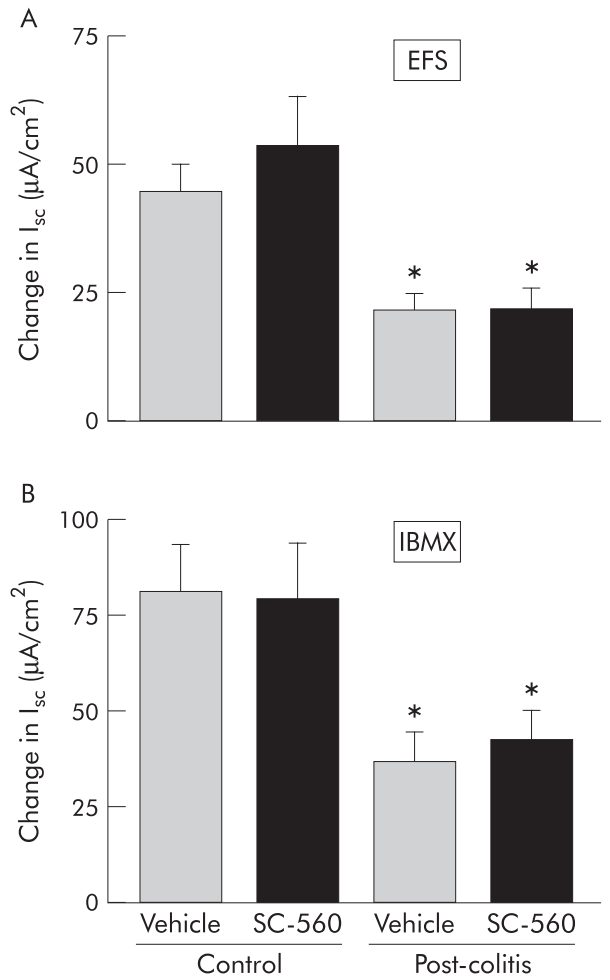

Figure 3 Effects of selective inhibition of cyclooxygenase 1 on changes in colonic short circuit current $\left(I_{s c}\right)$ in response to electrical field stimulation (EFS) (A) or isobutylmethylxanthine (IBMX) (B). Tissues harvested from rats six weeks after induction of colitis (post-colitis) and from age matched controls were studied. The serosal side of the tissues was exposed to SC-560 (300 nM) for 10 minutes prior to stimulation with EFS or IBMX. Values are mean (SEM), with 6-10 rats per group. ${ }^{*} \mathrm{p}<0.05$ versus the corresponding control group.

COX-2 was "primed" for induction in the post-colitis state. To test this possibility, we administered LPS to control and post-colitis rats, and then measured COX-2 expression. When control rats were given LPS, it caused a small (44\%) but significant increase in COX-2 expression in colonic tissue. In contrast, similar stimulation with LPS in the post-colitis group produced a $700 \%$ increase in COX-2 expression (fig 2).

\section{Role of COX-1 and COX-2 in post-colitis epithelial secretory hyporesponsiveness}

Consistent with previous observations of no difference between control and post-colitis colonic tissue in terms of permeability to small molecules, there were no differences between the two groups of rats in terms of conductance, as measured in the Ussing chamber experiments (control: 11.5 (1.2) $\mathrm{mS} / \mathrm{cm}^{2}$; post-colitis: 13.6 (1.3) $\mathrm{mS} / \mathrm{cm}^{2} ; \mathrm{n}=19$ per group). However, the ability of the colonic epithelium of postcolitis rats to secrete was markedly altered compared with controls. As shown in table 1 , the basal short circuit current was significantly reduced in post-colitis rats compared with controls. Moreover, as observed in previous studies, ${ }^{78}$ the distal colon from rats six weeks after TNBS administration exhibited hyporesponsiveness, in terms of chloride secretion, to both EFS and IBMX (fig 3). Preincubation of the tissue with SC-560, a selective COX-1 inhibitor, had no effect on the $\mathrm{I}_{\mathrm{SC}}$ response to either EFS or IBMX in control or post-colitis tissue. In contrast, preincubation of distal colon with celecoxib, a selective COX-2 inhibitor, reversed the hyporesponsiveness seen with both EFS and IBMX (fig 4). There was no significant difference between post-colitis tissue treated with celecoxib and control tissue treated with either
A
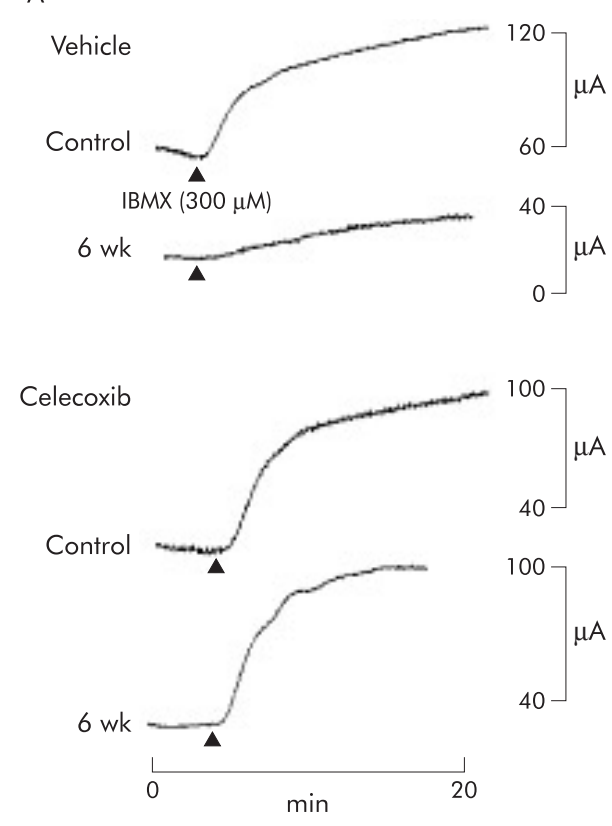

B
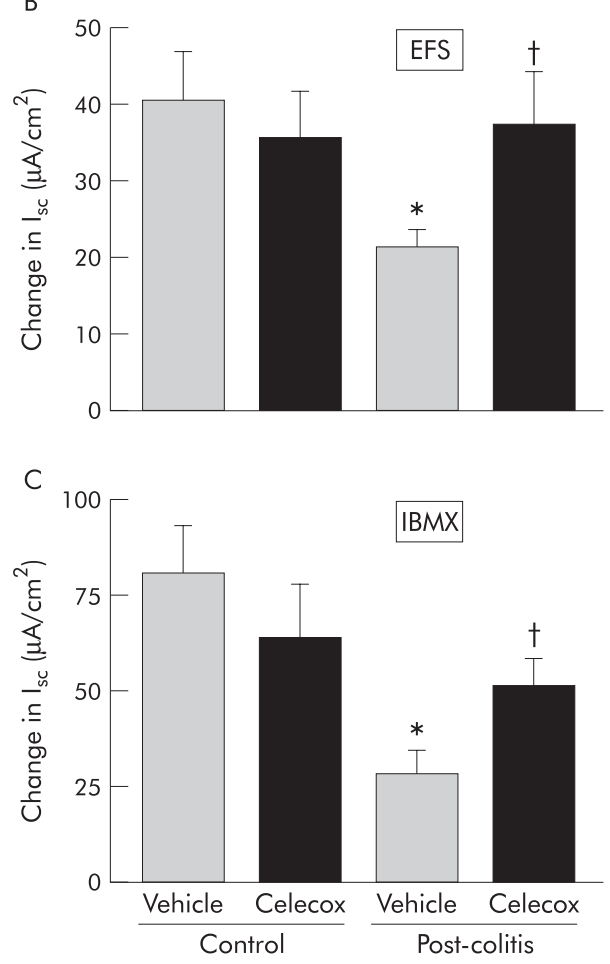

Figure 4 (A) Representative traces of short circuit current recording from colonic tissue mounted in Ussing chambers. The effects of vehicle and of celecoxib $(10 \mu \mathrm{M})$ are shown in both control and six week postcolitis rats. In each case the tissue was stimulated with isobutylmethylxanthine (IBMX $300 \mu \mathrm{M}$ ), eliciting an increase in the short circuit current. $(B, C)$ Effects of selective inhibition of cyclooxygenase 2 on changes in colonic short circuit current $\left(I_{\mathrm{sc}}\right)$ in response to electrical field stimulation (EFS; B) or IBMX (C). Tissues harvested from rats six weeks after induction of colitis (post-colitis) and from age matched controls were studied. The serosal side of the tissues was exposed to celecoxib (Celecox $10 \mu \mathrm{M})$ for 10 minutes prior to stimulation with EFS or IBMX. Values are mean (SEM), with $6-10$ rats per group. ${ }^{*} p<0.05$ versus the corresponding control group; $\mathrm{tp}<0.05$ versus the corresponding vehicle treated group. 

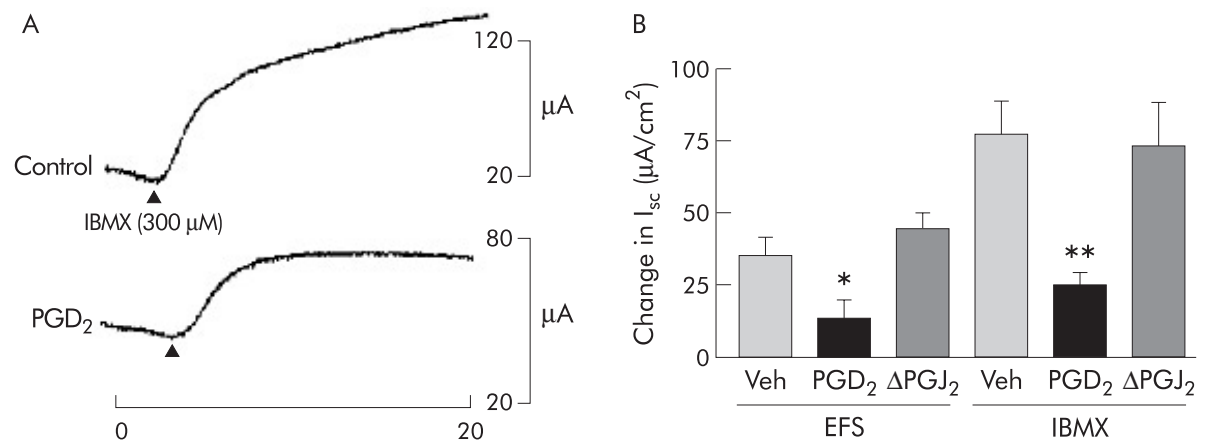

Figure 5 (A) Representative traces of short circuit current recording from colonic tissue from normal rats mounted in Ussing chambers. The effects of vehicle (control) or of prostaglandin $D_{2}\left(P D_{2} 1 \mu \mathrm{M}\right)$ are shown on the response to subsequent serosal application of isobutylmethylxanthine (IBMX $300 \mu \mathrm{M})$. (B) Effect of serosal pre-exposure to $P G D_{2}$ or 15 -deoxy- $\Delta^{12-14} P G J_{2}\left(\Delta P G J_{2} 1 \mu \mathrm{M}\right.$ for 10 minutes) on the change in colonic short circuit current $\left(I_{s c}\right)$ in response to electrical field stimulation (EFS) or IBMX. Values are mean (SEM), with 6-10 rats per group. ${ }^{*} p<0.05,{ }^{* *} p<0.01$ compared with vehicle group response to the same secretagogue.

vehicle or celecoxib. Neither celecoxib nor SC-560 significantly affected basal $\mathrm{I}_{\mathrm{sc}}$ (table 1) or basal conductance (with both drugs basal conductance stayed within the range 10$14 \mathrm{mS} / \mathrm{cm}^{2}$, in controls and post-colitis rats).

\section{Effects of $P G D_{2}$ and $\triangle P G J_{2}$ on colonic chloride secretion}

Pre-exposure of distal colon from control rats to $\mathrm{PGD}_{2}(1 \mu \mathrm{M})$ resulted in $\sim 60 \%$ decrease in basal short circuit current (table 1) and a similar decrease in the chloride secretory responses to EFS or IBMX (fig 5). Exposure to $\mathrm{PGD}_{2}$ did not significantly affect conductance (vehicle: 10.1 (1.2) $\mathrm{mS} / \mathrm{cm}^{2}$; $\mathrm{PGD}_{2}: 8.8(0.8) \mathrm{mS} / \mathrm{cm}^{2} ; \mathrm{n}=5$ per group). In contrast, preexposure of the distal colon to $\Delta \mathrm{PGJ}_{2}(1 \mu \mathrm{M})$, one of the major metabolites of $\mathrm{PGD}_{2}$, did not significantly affect basal $\mathrm{I}_{\mathrm{sc}}$ or conductance, or the $\mathrm{I}_{\mathrm{sc}}$ responses to EFS or IBMX (fig 5 ). Thus acute exposure of normal colonic tissue to $\mathrm{PGD}_{2}$ could mimic the hyporesponsiveness to EFS and IBMX that was observed in colonic tissue from post-colitis rats.

\section{Effects of COX-2 inhibition on bacterial colonisation and translocation}

Consistent with previous observations, ${ }^{8}$ aerobic bacterial colonisation of the distal colon was significantly increased in post-colitis rats compared with age matched controls. In this study, we found that the bacterial counts in the postcolitis group were 12 -fold greater than in controls (table 2). Furthermore, there was significantly greater (threefold) translocation of bacteria in the post-colitis group than in controls (table 2). Twice daily treatment with a selective inhibitor of COX-2 (rofecoxib) did not significantly change

Table 2 Role of cyclooxygenase 2 in elevated colonic bacterial colonisation and translocation following resolution of colitis

\begin{tabular}{lll}
\hline Group & $\begin{array}{l}\text { Total aerobes } \\
\left(\log _{10} \text { CFU/g) }\right.\end{array}$ & $\begin{array}{l}\text { Incidence of } \\
\text { translocation }(\%)\end{array}$ \\
\hline Control+vehicle & $5.40(0.34)$ & $2 / 10(20)$ \\
Post-colitis+vehicle & $6.47(0.31)^{*}$ & $8 / 11(73)^{*}$ \\
Post-colitis+rofecoxib & $6.05(0.29)$ & $2 / 11(18) \dagger$ \\
\hline
\end{tabular}

Colonic bacterial colonisation and translocation to the spleen were measured six weeks after trinitrobenzene sulphonic acid administration (controls were age matched). Treatment with rofecoxib $(3 \mathrm{mg} / \mathrm{kg}$ ) or vehicle was performed twice daily for the week prior to the rats being killed.

${ }^{*} \mathrm{p}<0.05$ versus the control group; $\mathrm{t} p<0.05$ versus the postcolitis+vehicle group. the numbers of aerobic bacteria in the distal colon of postcolitis rats. However, the incidence of bacterial translocation was reduced from $73 \%$ to $18 \%(\mathrm{p}<0.05)$, not significantly different from that observed in control rats (table 1 ).

\section{DISCUSSION}

The ability of the gastrointestinal epithelium to act as a barrier is critically important in terms of preventing infection. There are many components to epithelial defence, including the ability of the epithelium to secrete electrolytes, water, and mucus, and the ability (by virtue of tight junctions) to physically restrict the movement of microbes and microbial products into the lamina propria. Impairment of these defensive functions could therefore predispose an organism to bouts of infection and inflammation. Intestinal inflammation has been shown to produce prolonged alterations in smooth muscle function, which could contribute to symptom generation in disorders such as irritable bowel syndrome. ${ }^{24}$ In a series of studies over the past few years, we have sought to determine if a bout of inflammation of the intestine would similarly result in prolonged epithelial dysfunction. ${ }^{7}{ }^{8}$ Indeed, colitis induced by a hapten (TNBS) and enteritis induced by Nippostrongylus brasiliensis were both found to result in prolonged colonic epithelial secretory dysfunction, and in increase in bacterial translocation. ${ }^{78}$ In the present study, we provide evidence for a key role of COX-2, possibly via $\mathrm{PGD}_{2}$, in mediating the epithelial dysfunction that persists after resolution of TNBS induced colitis. Despite the absence of macroscopic and histological evidence of damage or inflammation, the colon of rats examined six weeks after TNBS administration did not function normally. Basal short circuit current and, as demonstrated previously, ${ }^{78}$ the colonic secretory responses to two stimuli were significantly reduced compared with those in healthy rats. Moreover, we confirmed our previous observation ${ }^{8}$ that there was a marked increase in bacterial translocation in the post-colitis rats. Treatment for one week with a selective COX-2 inhibitor reduced bacterial translocation to normal levels. Moreover, the epithelial hyposecretion was mimicked in vitro by $\mathrm{PGD}_{2}$ but not by its metabolite, $\Delta \mathrm{PGJ}_{2}$, and was reversed by a selective COX-2 inhibitor, but not a selective COX-1 inhibitor.

$\mathrm{PGD}_{2}$ has been suggested to be important in the resolution of acute inflammation, and it has further been suggested that this prostanoid is primarily derived from COX-2 in this setting. ${ }^{15}$ We previously showed that $\mathrm{COX}-2$ derived $\mathrm{PGD}_{2}$ played an important role in downregulating neutrophil infiltration into the mucosa in acute colitis, ${ }^{16}$ while Gilroy and colleagues ${ }^{15}$ showed an important role of $\mathrm{PGD}_{2}$ and $\Delta \mathrm{PGJ}_{2}$, derived from COX-2, in downregulating leucocyte 
influx in pleuritis. In the present study, we observed marked upregulation of $\mathrm{PGD}_{2}$ synthesis by the colon during the period of resolution of colitis and healing of colonic ulcers. The increase in $\mathrm{PGD}_{2}$ synthesis was completely abolished by treatment with rofecoxib, indicating that it was derived primarily from COX-2. A role for COX-2 in the resolution of colitis is also consistent with our previous observation that selective inhibitors of COX-2 exacerbated TNBS induced colitis in the rat. ${ }^{25}$ Surprisingly, the increase in COX-2 expression in post-colitis tissue was only of the order of $\sim 60 \%$ above that in colonic tissue from healthy rats. However, expression of COX-2 appeared to be "primed" in the post-colitis setting as administration of LPS resulted in a much more robust $(700 \%)$ increase in expression in postcolitis rats compared with that in healthy controls stimulated with LPS.

$\mathrm{PGD}_{2}$ has well characterised inhibitory effects on epithelial secretion in the dog and rat. ${ }^{17}{ }^{18}$ Our observation that $\mathrm{PGD}_{2}$ reduced IBMX and EFS stimulated chloride secretion is consistent with previous observations from rat studies. ${ }^{19}$ There is some controversy as to which of the two identified $\mathrm{PGD}_{2}$ receptors mediate the inhibitory effects of $\mathrm{PGD}_{2}$ on epithelial secretion, ${ }^{26}$ and from the results of the present study we cannot shed light on this issue. However, we did observe that $\Delta \mathrm{PGJ}_{2}$ did not suppress epithelial secretion when tested at the same concentration as $\mathrm{PGD}_{2}$. This indicates that the inhibitory effects of $\mathrm{PGD}_{2}$ did not occur as a consequence of metabolism to $\Delta \mathrm{PGJ}_{2}$.

The observed changes in colonic epithelial secretion may have been produced by changes in the epithelium itself, and/ or through changes in several mucosal elements that can influence epithelial function. For example, the enteric nervous system and mucosal stromal and immune cells (for example, myofibroblasts, mast cells) can influence epithelial responses to secretagogues and to EFS. In a previous study, ${ }^{7}$ we noted that secretory hyporesponsiveness to EFS, IBMX, and carbachol in tissues from post-colitis rats was not influenced by pre-exposure of the tissues to tetrodotoxin. While this suggests that enteric neurones are not responsible for the post-colitis hyporesponsiveness, one cannot rule out a contribution of tetrodotoxin insensitive nerves, or of other extra-epithelial cells in modulating epithelial function in the post-colitis state. Similarly, the mechanism underlying the prevention of bacterial translocation in post-colitis rats treated with rofecoxib has not been identified. It is possible that normalisation of colonic secretion, as the in vitro studies demonstrated, resulted in the decrease in bacterial translocation. However, it is also possible that rofecoxib reduced bacterial translocation through other actions on the epithelium or on non-epithelial cells.

In an earlier study, we observed that selective suppression of iNOS could also significantly reduce post-colitis bacterial translocation, and partially reverse secretory hyporesponsiveness. ${ }^{78}$ There may be a link between the role of NO production in post-colitis tissue and the observed importance of COX-2. NO derived from iNOS has been reported to mediate the intestinal epithelial hyposecretion in experimental radiation enteritis, ${ }^{14}$ and to modulate epithelial barrier function..$^{27}$ The latter has been shown to be a direct effect of NO on tight junctions. ${ }^{29}$ Thus suppression of NO synthesis would be expected to reverse some of the observed abnormalities in epithelial function in post-colitis rats. However, NO derived from iNOS could also contribute to the COX-2 associated changes in epithelial secretion and barrier function. NO has been shown to stimulate COX activity in a mouse macrophase cell line and in vivo in the rat. ${ }^{30} 31$ Thus increased iNOS can lead to increased COX-2 activity while suppression of iNOS activity results in lower COX-2 activity. ${ }^{30}$ Interestingly, iNOS and COX-2 have recently been suggested to mediate alterations in barrier and transport properties of the human intestinal epithelium caused by enteroinvasive bacteria, and these alterations could be partially reversed by inhibitors of either iNOS or COX-2. ${ }^{32}$ Moreover, COX-2 has been implicated as a mediator of the smooth muscle dysfunction that persists after a bout of inflammation. ${ }^{33}$

While not the focus of the present study, it is important to note that prolonged elevation of COX-2 has been implicated in proliferative disorders of the large intestine. Also, metabolites of $\mathrm{PGD}_{2}$ (such as $\Delta \mathrm{PGJ}_{2}$ ), acting at the PPAR $\gamma$ receptor, have similarly been implicated as contributing to such disorders. ${ }^{34}$ COX-2 appears to play an important role in the pathogenesis of colorectal cancer, ${ }^{35}$ the incidence of which is markedly elevated in colitis patients. ${ }^{36}$ We observed that COX-2 was "primed" in the post-colitis scenario, such that expression was increased profoundly following stimulation with LPS (relative to healthy controls). Thus we have observed two key alterations that could contribute to proliferative changes in the colon of rats following resolution of colitis, namely, increased bacterial translocation (thus exposure to bacterial endotoxin) and an increased sensitivity to stimulation by bacterial endotoxin in the context of COX-2 expression. The underlying mechanisms for the priming of COX-2 have not yet been identified, and certainly warrant further study.

In summary, the results of the present study further demonstrate the important role the COX-2 derived products in regulating epithelial function. The marked elevation of bacterial translocation in post-colitis rats was reversed by selective inhibition of COX-2, as was epithelial secretory hyporesponsiveness. Whether or not there is a causative link between secretory hyporesponsiveness and impaired barrier function is not yet clear. Colonic secretion of water, which is driven by electrolyte secretion, has been suggested to be very important in mucosal defence, by diluting toxins, flushing away luminal microbes, and delivering secretory IgA. ${ }^{2}$ In addition to the potential role of COX-2 in mediating epithelial proliferative changes following colitis, this enzyme and one of its products, $\mathrm{PGD}_{2}$, appear to contribute significantly to the prolonged alterations in epithelial function that follow a bout of colitis. COX-2 and possibly $\mathrm{PGD}_{2}$ may therefore represent rational therapeutic targets for preventing these prolonged alterations in epithelial function, which may contribute to the relapses of colonic inflammation that are common in ulcerative colitis and Crohn's disease.

\section{ACKNOWLEDGMENTS}

This work was support by grants from the Canadian Institutes of Health Research (CIHR) and the National Science and Engineering Research Council. Dr Zamuner is supported by a CIHR/Janssen Pharmaceutica/Canadian Association of Gastroenterology Fellowship. Dr Wallace is an Alberta Heritage Foundation for Medical Research (AHFMR) Scientist and Dr MacNaughton is an AHFMR Senior Scholar.

\section{Authors' affiliations \\ S R Zamuner*, N Warrier*, A G Buret, W K MacNaughton, J L Wallace, Mucosal Inflammation Research Group, University of Calgary, Calgary, Alberta, T2N 4N1, Canada}

*S R Zamuner and N Warrier contributed equally to this paper.

\section{REFERENCES}

1 Kunzelmann K, Mall M. Electrolyte transport in the mammalian colon: mechanisms and implications for disease. Physiol Rev 2002;82:2945-89.

2 Chang EB, Rao MC. Intestinal water and electrolyte transport: mechanisms of physiological and adaptive responses. In: Johnson LR, ed. Physiology of the gastrointestinal tract, 3rd edn. New York: Raven Press, 1994:2027-81. 
3 Bell CJ, Gall DG, Wallace JL. Disruption of colonic electrolyte transport in experimental colitis. Am J Physiol Gastrointest Liver Physiol 1995;31:G622-30

4 Kachur JF, Keshavarzian A, Sundaresan R, et al. Colitis reduces short-circuit current response to inflammatory mediators in rat colonic mucosa. Inflammation 1995; 19:245-60.

5 Stein J, Reis J, Barrett KE. Disruption of intestinal barrier function associated with experimental colitis: possible role of mast cells. Am J Physiol Gastrointest Liver Physiol 1998;274:G203-9.

6 MacNaughton WK, Lowe SS, Cushing K. Role of nitric oxide in inflammationinduced suppression of secretion in a mouse model of acute colitis. Am J Physiol 1998;275:G1353-60.

7 Asfaha S, MacNaughton WK, Appleyard CB, et al. Persistent epithelial dysfunction and bacterial translocation after resolution of intestinal inflammation. Am J Physiol 2001;281:G635-44.

8 Asfaha S, Bell CJ, Wallace JL, et al. Prolonged colonic epithelial hyporesponsiveness after colitis: role of inducible nitric oxide synthase. Am J Physiol 1999;276:G703-10.

9 Smith PL, Montzka DP, McCafferty GP, et al. Effect of sulfidopeptide leukotrienes $D_{4}$ and $E_{4}$ on ileal ion transport in vitro in the rat and rabbit. Am J Physiol 1988;255:G175-83.

10 MacNaughton WK. Nitric oxide-donating compounds stimulate electrolyte transport in the guinea pig intestine in vitro. Life Sci 1993;53:585-93.

11 Hardcastle J, Hardcastle PT. Involvement of prostaglandins in histamineinduced fluid and electrolyte secretion by rat colon. J Pharm Pharmacol 1988;40:106-10.

12 Zimmerman TW, Binder HJ. Serotonin-induced alteration of colonic electrolyte transport in the rat. Gastroenterology 1984;86:310-17.

13 Schirgi-Degen A, Beubler E. Significance of nitric oxide in the stimulation of intestinal fluid absorption in the rat jejunum in vivo. $\mathrm{Br} J$ Pharmacol 1995; 114:13-18.

14 Freeman SL, MacNaughton WK. lonizing radiation induces iNOS-mediated epithelial dysfunction in the absence of an inflammatory response. Am J Physiol 2000;278:G243-50.

15 Gilroy DW, Colville-Nash PR, Willis D, et al. Inducible cyclooxygenase may have anti-inflammatory properties. Nat Med 1999;5:698-701

16 Ajuebor MN, Singh A, Wallace JL. Cyclooxygenase-2-derived prostaglandin $\mathrm{D}_{2}$ is an early anti-inflammatory signal in experimental colitis. Am J Physiol 2000;279:G238-44.

17 Keenan CM, Rangachari PK. Contrasting effects of $P G E_{2}$ and $P G D_{2}$ : ion transport in the canine proximal colon. Am J Physiol 1991 260:G481-8.

18 Goerg KJ, Diener C, Diener M, et al. Antisecretory effect of prostaglandin $D_{2}$ in rat colon in vitro: action sites. Am J Physiol 1991;260:G904-10.

19 Morris GP, Beck PL, Herridge MS, et al. Hapten-induced model of chronic inflammation and ulceration in the rat colon. Gastroenterology 1989:96:795-803.
20 Wallace JL, MacNaughton WK, Morris GP, et al. Inhibition of leukotriene synthesis markedly accelerates healing in a rat model of inflammatory bowel disease. Gastroenterology 1989;96:29-36.

21 Perdue MH, Chung M, Gall DG. Effect of intestinal anaphylaxis on gut function in the rat. Gastroenterology 1984;86:391-7.

22 Katayama M, Xu D, Specian RD, et al. Role of bacterial adherence and the mucus barrier on bacterial translocation: effects of protein malnutrition and endotoxin in rats. Ann Surg 1997;225:317-26.

23 Fiorucci S, de Lima OM jr, Mencrelli A, et al. Cyclooxygenase-2-derived lipoxin $A_{4}$ increases gastric resistance to aspirin-induced damage. Gastroenterology 2002;123:1598-606.

24 Grossi L, McHugh K, Collins SM. On the specificity of altered muscle function in experimental colitis in rats. Gastroenterology 1993;104:1049-56.

25 Reuter BK, Asfaha S, Buret A, et al. Exacerbation of inflammation-associated colonic injury in rat through inhibition of cyclooxygenase-2. J Clin Invest 1996;98:2076-85.

26 Rangachari PK, Betti P-A. Biological activity of metabolites of $P G D_{2}$ on canine proximal colon. Am J Physiol 1993;264:G886-94.

27 Unno N, Wang H, Menconi MJ, et al. Inhibition of inducible nitric oxide synthase ameliorates endotoxin-induced gut mucosal barrier dysfunction in rats. Gastroenterology 1997;113:1246-57.

28 Chen LW, Hsu CM, Wang JS, et al. Specific inhibition of iNOS decreases the intestinal mucosal peroxynitrite level and improves the barrier function after thermal injury. Burns 1998;24:699-705.

29 Salzman AL, Menconi MJ, Unno N, et al. Nitric oxide dilates tight junctions and depletes ATP in cultured Caco-2 intestinal epithelial monolayers. Am J Physiol 1995;268:G361-73.

30 Salvemini D, Misko TP, Masferrer JL, et al. Nitric oxide activates cyclooxygenase enzymes. Proc Natl Acad Sci U S A 1993;90:7240-4.

31 Salvemini D, Settle SL, Masferrer JL, et al. Regulation of prostaglandin production by nitric oxide; an in vivo analysis. Br J Pharmacol 1995;114:1171-8.

32 Resta-Lenert S, Barrett KE. Enteroinvasive bacteria alter barrier and transport properties of human intestinal epithelium: role of iNOS and COX-2. Gastroenterology 2002;122:1070-87.

33 Barbara G, De Giorgio R, Deng Y, et al. Role of immunologic factors and cyclooxygenase 2 in persistent postinfective enteric muscle dysfunction in mice. Gastroenterology 2001;120:1729-36.

34 Clay CE, Namen AM, Fonteh AN, et al. 15-deoxy- $\Delta^{12,14} \mathrm{PGJ}_{2}$ induces diverse biological responses via PPAR $\gamma$ activation in cancer cells. Prostaglandins Other Lipid Mediat 2000;62:23-32.

35 Krause WF, DuBois RN. The molecular basis for prevention of colorectal cancer. Clin Colorectal Cancer 2001;1:47-54.

36 Hinton JM. Risk of malignant change in ulcerative colitis. Gut 1966;7:427-32. 